\title{
Partilha de boas práticas: a poesia na promoção da escrita criativa
}

\author{
Ana Regina Pires \\ Departamento de Didática e Organização Escolar, Universidade de Santiago de Compostela (USC), España
}

\begin{abstract}
Resumo
O presente estudo explora a língua portuguesa a nível da escrita mais concretamente da escrita de poemas. Articulamos a escrita com a poesia para promovermos o desenvolvimento holístico da criança no âmbito do Ensino Básico - $1 .^{\circ}$ Ciclo. Procuramos não só formá-la a nível cognitivo, linguístico, cultural mas inclusive, a nível artístico, afetivo, ético e axiológico. Através da metodologia de investigação-ação desenvolvemos um estudo, numa escola do Ensino Básico - $1 .^{\circ}$ Ciclo, com alunos que frequentam o $1 .^{\circ}$ ano de escolaridade. No âmbito da investigação doutoral, realizamos um estudo exploratório, onde dinamizamos atividades, desenvolvemos estratégias e levamos as crianças a participarem em sessões poéticas.

Palavras clave: poesia, escrita, imaginação, socialização.
\end{abstract}

\section{A poesia: um conceito polissémico}

O conceito polissémico - poesia - relaciona-se com a palavra poïesis que significa “fazer” (Neto, 2006). De acordo com o Dicionário Etimológico da Língua Portuguesa (Almeida, 1995, p. 389), o vocábulo "poesia" deriva do "étimo grego poiesis que significa criação, acto de fazer, de fabricar”.

Nos dicionários mais arcaicos, a poesia é definida através da arte de “ (...) fazer obras em verso” (Lettre, cit. por Neto, 2006, p. 16). Com o passar dos anos o significado alterou-se relacionando-se com uma vertente musical, sonora e rítmica.

Para Jean (1995) a poesia consiste num ato criador, inovador, mimético, ritmado e melódico em que “(...) sem as desordens da afectividade e as irrupções do imaginário, sem a loucura do impossível, não existiria entusiasmo, criação, invenção, amor e poesia.” (Morin, 1999, p. 9). Esta assume-se como o alicerce de toda a linguagem. Assim, através do imaginário e do sonho permite aceder ao mundo real transparecendo sem ambiguidades toda a verdade, como advoga Dias (2008).

Na perspetiva de Nancy (2005), a definição de poesia apresenta-se polissémica. Isto porque, o autor transporta para a sua "combinação de palavras" um determinado sentido e significado que, por sua vez, é transformado pelo leitor que o adapta à sua realidade, experiência conferindo-lhe um significado próprio. A poesia apresenta-se, assim, como um jogo de palavras que emerge, naturalmente. Este jogo de palavras rodopia num corpo lúdico através da voz da expressão poética. Deste modo, a poesia surge associada a um jogo estabelecido a partir de uma relação conexa entre as palavras. O jogo existe desde que se introduz a linguagem da repetição dos sons que possibilita o gosto na audição da poesia, em que todas as combinações são possíveis.

A “Poesia não é sentimento, é linguagem. Não é experiência vivida, é experiência de linguagem. Ela não se faz com sentimentos, nem também com ideias, mas com palavras, apenas com palavras.” (Belo cit. por Dias, 2008, p. 15)

\section{Como viver o domínio poético?}

A boa qualidade das relações promovidas entre os pares, a socialização, a exequível comunicação, a afetividade, o prazer, apresentam-se como as linhas mestras da implementação de uma aula livre, espontânea e natural veiculada/sustentada pela/na poesia. Por sua vez, torna-se imprescindível que o professor aproveite o momento ótimo, a ocasião «clímax», as ideias estimulantes conducentes à criação de um clima de confiança, de condições materiais necessárias que promovam a emergência do gosto pela poesia. Ao promover o contacto precoce com o texto poético em que brota o desejo pelo "prazer estético", pela "fruição da profundidade”, pela "beleza da arte” que emanam a partir da sensibilização e descoberta por este universo poético (Franco, 1999, p. 83), o professor induz, de forma criativa e prazerosa, a criança a um desenvolvimento global.

De acordo com Held (cit. por Guedes, 2002, p. 53): a poesia “ «é indispensável à construção duma criança que mais tarde saiba inventar o homem.»”. Isto porque, a sua "linguagem transgressiva" e a "metamorfose conjunta das palavras" constituem uma "provocação e força, pelo prazer, o imaginário infantil” que provocam na criança uma "tendência para a criatividade".

A escola apresenta-se, pois, como um espaço predileto para a formação do leitor, para a fruição da leitura, para a descoberta do mundo. Necessita, para isso, de promover estratégias conducentes ao contacto da criança com os livros de foro estético que extravasem o mero caráter pedagógico, frequentemente valorizado na escola. Assim, o livro de cariz estético, permite à criança transbordar os limites pontiagudos da realidade com vista à emergência da criatividade e ao conhecimento de um novo mundo, por ela idealizado (Azevedo, 2006).

É fundamental que o “ensino da poesia” não se baseie na análise excessiva de textos poéticos, ou mesmo na memorização minuciosa do poema. Pelo contrário, ao abordar a poesia de forma lúdica e intencional emerge, espontaneamente da vontade do ser humano, o seu potencial. Descoberta a partir da espontaneidade de uma voz, ela incita à emoção e ao sonho (Morin, 2001).

Segundo Franco (1999, p. 57), existem três áreas necessárias para que o ingresso da criança no domínio poético se efetive: o ambiente de turma (sem barreiras, ênfase ao diálogo, estímulo da autoconfiança, partilha, etc.); a relação da criança com o mundo (recriação estética); e o uso da linguagem (capacidade de autoescuta, musicalidade das palavras, gramática implícita, jogos de mímica, etc.). 
A função realizada por cada área desempenha um papel crucial na formação do aluno, bem como, a comunicabilidade promovida entre a trilogia supracitada. Por outro lado, no que concerne às condições materiais, pode enumerar-se três tipos de condições: o tempo, o espaço e a liberdade. Estas condições permitem a emergência autónoma ou limitada na promoção deste meio estimulante: a poesia (Cosem, 1980).

No âmbito da "criação de um clima de confiança”, as fábulas de La Fontaine ocupam um lugar central no contexto pedagógico; a fábula plasma a realidade sem no entanto ocultar as sementes lançadas no fértil campo da imaginação e fantasia. A moral contida na fábula e o uso de uma linguagem simbólica persuadem as crianças e permitem que estas acedam a ensinamentos úteis para o seu desenvolvimento global (Duborgel, 1995).

\section{A poesia na sala de aula: implicações pedagógicas}

Segundo Cosem (1980), a poesia é imprescindível ao desenvolvimento cognitivo, afetivo e social da criança; estreita a relação promovida entre o adulto e a criança; bem como a relação acionada entre os pares. Propicia, também, situações ricas e estimulantes que permitem à criança apropriar-se da linguagem e expressar-se pelo poder do imaginário, da criatividade, estimulando a formação da personalidade infantil, bem como, a possibilidade de inventar novas relações com o mundo, tendo em vias a conquista da realidade.

Para Gomes (1999), pode aludir-se à poesia, à luz de um sentimento humanista, isto porque a dinâmica promovida entre pares, a integração de alunos com dificuldades de aprendizagem, o caráter interdisciplinar e articulatório contribuem para o despertar do gosto do aluno pela aprendizagem. No âmbito das potencialidades do texto poético podem enumerar-se as seguintes: aperfeiçoamento da leitura oral; aperfeiçoamento da articulação e dicção; etc.

A poesia reforça e estimula a aprendizagem das crianças. Caminha-se, vertiginosamente para um tecido educativo menos sério, estandardizado em que o poder fértil do sonho, da distração, da ausência de rigor extravasa a realidade e permite a emergência de um mundo mais belo, colorido e atrativo. A poesia surge, porém como uma motivação, uma oportunidade de persuadir a criança para este campo do poético, como alicerce da educação e do desenvolvimento da criança permitindo-a “ «entrar na língua»”. Como testemunham alguns profissionais da educação, a poesia torna possível a emergência da linguagem (Jean, 1995).

A poesia pretende proporcionar às crianças múltiplos contactos com o mundo que a rodeia; despertá-la para a curiosidade de saber mais; assim como, proporcionar experiências singulares, ricas e multidisciplinares. Mas, para que a poesia seja uma prática constante no ensino, necessitam-se de conhecer algumas caraterísticas que possam levar a cabo a implementação de atividades de caráter lúdico-interativo-pedagógico conducentes ao desenvolvimento global da criança.

Em síntese, a poesia encontra-se pouco explorada no contexto de sala de aula. Todavia, compete ao professor adotar uma atitude criativa e inovadora com vista a persuadir os seus alunos para o processo de ensino e aprendizagem por intermédio do ensino da poesia (Cosem, 1980). De igual modo, é necessário que os professores trabalhem a poesia na sala de aula a fim de promoverem o desenvolvimento de habilidades de percepção sensorial da criança, o sentido estético, bem como as competências leitoras e, consequentemente, simbólicas. A interação precoce com a poesia é responsável pelo “ (...) desenvolvimento pleno da capacidade linguística da criança” (Mermelstein, 2015, p. 8) que através do seu contacto com a linguagem conotativa promove um olhar mais atento e sensível sobre o mundo.

\section{Atividades poéticas - Jogos poéticos}

Para Jean (1995), a atividade poética perspetiva-se como um momento de descontração e alegria. Encontra-se afastada do medo, da angústia e do receio de esquecer uma ou outra palavra que provém da recitação dos exercícios escolares. A poesia apresenta-se, assim, como uma dimensão lúdica da linguagem e, por meio dos jogos poéticos promove a construção de múltiplos conhecimentos.

Os jogos poéticos promovem a construção de aprendizagens significativas, bem como apresentam-se como um treino progressivo no que concerne à escrita criativa. No entanto, é necessário que os professores se encontrem sensibilizados para este género literário. Não se pretende que estes sejam "poetas federados”, mas sim que perspetivem a poesia como um momento de aquisição, crescimento e contínua formação pessoal e artística. Neste âmbito, a escola necessita de promover atividades indutoras no gosto pela poesia: tertúlias literárias, ações de formação contínuas, declamação interescolas, etc. (Couto, 2007).

Importa que o profesor dinamize metodologias e estratégias com vista ao alcance dos objetivos preconizados. Nesta medida apresentam-se algumas estratégias/ metodologias que aproximam a criança da poesia, tais como: jogos poéticos individuais/ coletivos (inventar palavras, etc.); sequências de respiração (inspiração/ expiração respiratória, controlo do fôlego, etc.); sequências de dicção (colocação de voz, articulação, perceção do ritmo, etc.); sequência de investigação dos ritmos (ex.: ritmos semânticos); bem como, o texto poético (escutar/ ler/ produzir) (Jean, 1995).

Concomitantemente, Guedes (2002, p. 52) realça a importância do professor promover o espirito criativo da criança através do envolvimento em jogos poéticos, tais como: jogos de som; jogos de letras e palavras; jogos visuais (ex.: jogos do espelho); jogos do concreto e de observação; jogos de rigor; entre outros.

Nesta linha, Guedes (2002) e Couto (2007) partilham do mesmo pensamento ao enumerarem as potencialidades promovidas pelo jogo poético/ fonético que favorece o/ a: imaginação; liberdade corporal; aproximação entre o dito "bom” e "mau” aluno; cooperação; sentido de responsabilidade; libertação de energia; exploração entusiasmada; processo em detrimento do produto; autoconfiança; espírito criativo; vínculo com a Língua Materna; espontaneidade; melhor 
conhecimento de si, dos outros e do mundo; espírito crítico; etc.

Em rescaldo, o papel dos jogos poéticos consiste no desbloqueamento da escrita, da oralidade, da estimulação da criatividade (idem). Os jogos permitem, assim desencadear processos de atenção e atribuir vida a um corpo, uma vez que se apresentam como o trampolim necessário para a emergência da linguagem. Através da atividade lúdica constata-se que criança não baliza o campo existente entre a realidade e o imaginário. Deste modo, torna-se necessário o recurso aos jogos poéticos com vista à conquista da língua, bem como no desbloqueio articulatório da criança (Guedes, 2002).

A introdução aos jogos poéticos pretende, assim desbloquear o imaginário infantil conducente ao despoletar da criatividade verbal e pictórica. Todavia, o educador deve romper com regras estandardizadas de ensino que condicionam o processo educativo. Somente, assim promover-se-á o contacto e envolvimento em jogos poéticos com vista ao alcance do sucesso educativo.

\section{Objetivos do ensino da poesia}

Parafraseando Neto (2006) os objetivos propostos consistem em: desenvolver a imaginação, estruturar o desejo, proporcionar prazer, promover a afetividade, desenvolver a sensibilidade, despoletar o poder criador da criança, formar o sentido estético da criança, sensibilizar para o universo das artes e promover a socialização.

Concomitantemente, Guedes (2002, p. 34), identifica os seguintes objetivos gerais para a poesia: “(...) favorecer o poder criador da criança; desenvolver a imaginação e sensibilidade; iniciar a criança à arte em geral; formar o sentido estético da criança (formar, mas não conformar).”

A poesia promove o desenvolvimento socioafetivo (a criança interroga-se sobre o que aprende, julgando criticamente o que lê; integra-se socialmente através da palavra; exprime por iniciativa própria ideias adaptando o seu discurso aos seus pares); o desenvolvimento da competência da Escrita (aumento do léxico; distinção do texto poético dos demais textos; opina acerca do texto poético; conhece o vocabulário e aplica-o; reconstrói palavras; etc.); desenvolvimento da competência da Leitura (desbloqueia os receios de ler em voz alta; controla a respiração; articula corretamente as sílabas; etc.); entre outras vantagens conducentes ao desenvolvimento holístico (cognitivo, afetivo e social) deste ser em transformação - a criança (Neto, 2006).

\section{Vantagens do ensino da poesia}

Para Guedes (2002) as vantagens do ensino da poesia excedem, certamente as suas expetativas. Isto porque, a poesia é o motor do (a): imaginação infantil (relação estreita com o desenvolvimento da linguagem e inteligência); memória (curto/ médio/ longo prazo); concentração (a poesia apela à concentração); descoberta de si e dos outros (combate à instabilidade/ promoção da socialização); melhor conhecimento acerca dos alunos, por parte do professor (o aluno ao interpretar poemas desvenda o seu mundo e dá-o a conhecer a si e aos outros); desbloqueio da espontaneidade; vínculo efetivo com a Língua Materna (por ex.: os jogos poéticos); sensibilidade estética; formação integral do aluno ("«na poesia por excelência se plasmam sentimentos, emoções, a invenção e as especulações do intelecto, na sua vertigem ou num contínuo diálogo com o mundo»”) (Gomes, cit. por idem: 35); formação de pessoas independentes (a liberdade de pensamento/ expressão é consentida pelo poder da poesia); comunicação (diálogo estabelecido entre os pares; comunicação promovida a partir dos jogos poéticos); interdisciplinaridade (articulação plena entre as várias áreas curriculares); entre outras potencialidades que estreitam a relação com a Língua Materna a fim da promoção do desenvolvimento global do aluno.

\section{Da teoria à praxis - A metodologia de investigação-ação}

A metodologia selecionada para este trabalho consiste numa metodologia de investigação-ação. Esta apresenta-se como uma modalidade desencadeada por um sujeito que busca construir conhecimento e reunir informação com vista a solucionar um problema/ situação (Bogdan e Biklen, 2006). Neste âmbito, surge a necessidade de promover-se, não somente uma investigação para a ação mas, acima de tudo, desenvolver-se uma investigação pela ação e permitir a existência de um mundo mais humano, mais poetizado.

\section{Trabalho na sala de aula}

Através da metodologia de investigação-ação promovemos um estudo, numa escola do Ensino Básico - 1. ${ }^{\circ}$ Ciclo, com alunos que frequentam o $1 .^{\circ}$ ano de escolaridade. No âmbito da investigação doutoral, realizamos um estudo exploratório, onde dinamizamos atividades, desenvolvemos estratégias e levamos as crianças a participarem em sessões poéticas de caráter lúdico-pedagógico, desencadeando uma escrita livre, poética, criativa que faça uso da imaginação, da fantasia, que permita a expressão dos sentimentos mais profundos de cada criança.

\section{As três fases de envolvência da poesia}

Em contexto de sala de aula, Couto (2007) perspetiva a poesia não como um fim em si mesmo, mas como um passaporte para os outros domínios educativos. Nesta linha identifica três fases: Metapoesia: a criança habitua o ouvido à leitura/audição de poesia e de metapoesia; Produção: a criança envolve-se na produção de textos poéticos (concebe jogos indutores, seleciona estruturas, define instruções, implementa os jogos/ atividades, etc.); Visibilidade: numa fase ulterior, o professor confere visibilidade ao trabalho elaborado pela criança através da: organização de uma pasta (pessoal ou de turma), criação de um jornal da poesia (escolar e extraescolar), promoção de «Tertúlias Poéticas» (convite a um poeta), entre outras potencialidades pedagógicas asseguradas pela criação de momentos dedicados à componente poética. 


\section{Atividades indutoras no despertar do gosto pelo texto poético}

Couto (2007, p. 2) enumera um processo sequencial de atividades indutoras ao texto poético que podem introduzir-se na sala de aula, tais como: leitura e realização de tentativas de produção de textos de metapoesia (desmistificar; sensibilizar e motivar); leitura de poesia (de autores diversificados; encontrada na internet; do próprio profesor); produção de textos poéticos (conceber jogos indutores, pedir sugestões aos alunos, selecionar estruturas, definir instruções, implementar os jogos/ atividades, corrigir os textos conseguidos); atribuição de visibilidade ao trabalho (organizar uma pasta pessoal ou de turma; criar um jornal de poesia aberto à comunidade em geral - escolar e extraescolar; criar um quadro num dos espaços escolares; promover a correspondência poética entre turmas; construir uma página na internet, divulgando-a a outras escolas, com espaço de partilha criativa e interativa; promover "Tertúlias Poéticas” (convidar um poeta...); registar poemas dos/ as alunos/ as e soltá-los ao vento (balões).”

\section{Conclusão}

As atividades desencadeadas promoveram o desenvolvimento global da criança, nomeadamente no que concerne às suas competências linguísticas e comunicativas. Todavia, pensamos que ainda existe um longo caminho a percorrer, uma vez que o número de atividades desenvolvidas consiste numa amostra restrita que visa elucidar para as distintas fases constituintes da dinamização de atividades poéticas ao longo da recepção e produção de textos poéticos. Em suma, deixamos uma porta aberta para todos os interessados na temática, propondo inclusive que os educadores estimulem o desejo que brota das crianças em Aprender a Aprender, Aprender a Fazer e Aprender a Ser com vista ao seu desenvolvimento global na quimera de uma integração plena e harmoniosa na sociedade em perpétua mutação.

\section{Referencias}

Almeida, R.C. (1995). Dicionário Etimológico da Língua Portuguesa. São Paulo: Ática.

Bogdan, R \& Biklen, S. (2006). Investigação Qualitativa em Educação. Porto: Porto Editora.

Cosem, M. (1980). O poder da poesia. Coimbra: Livraria Almedina.

Couto, J. M. (2007). Para uma pedagogia do texto poético. Canelas: Escola Superior de Educação Jean Piaget (texto policopiado).

Dias, S. (2008). O que é a poesia? Coimbra: Pé de Página Editores.

Duborgel, B. (1995). Imaginário e pedagogia. Lisboa: Instituto Piaget.

Franco, J. A. (1999). A poesia como estratégia. Porto: Campo das Letras.

Guedes, T. (2002). Ensinar a poesia. Porto: Edições ASA.

Jean, G. (1995). Na escola da poesia. Lisboa: Instituto Piaget.

Mermelstein, M. (2015). Subsídios para trabalhar a poesia na sala de aula. São Paulo, Brasil. http://www.crmariocovas.sp.gov.br/lei_a.php?t =020\#artigo.

Morin, E. (1999). Amor, poesia, sabedoria. Lisboa: Instituto Piaget.

Morin, E. (2001). O desafio do século XXI. Lisboa: Instituto Piaget.

Nancy, J. (2005). Resistência da poesia. Viseu: Edições Vendaval.

Neto, L. (2006). Olhares poéticos da infância. Porto: Papiro Editora. 